\title{
Conta Certa
}

\section{Desenvolvimento de Jogo em Realidade Aumentada para Museu Interativo.}

\author{
Beatriz de Almeida Pacheco \\ Faculdade de Computação e Informática \\ Universidade Presbiteriana Mackenzie \\ São Paulo, Brasil \\ bia.pacheco@mackenzie.br
}

\author{
Maurício Marengoni \\ Faculdade de Computação e Informática \\ Universidade Presbiteriana Mackenzie \\ São Paulo, Brasil \\ mmarengoni@mackenzie.br
}

\begin{abstract}
This paper presents an augmented reality application as an interactive game which is installed in the Accounting Memory Center in São Paulo. This game applies part of the interactive concepts and construction challenges in order to make the game attractive and esthetically interesting for the user. This game allows and interesting, stimulating and educational environment for kids in pre-school age. The paper presents the motivation, and design concepts used as well as details in the implementation aspects of the game. At the end some user views and impressions are presented.
\end{abstract}

Keywords-component; Augmented Reality, Games, interaction, Interactive museums

\section{INTRODUÇÃO}

Os Museus, desde suas origens, são vistos como instituições que atuam como vitrines dos processos culturais e educativos das sociedades. Ter contato com as informações e atividades que estas instituições apresentam nos permite ter subsídios para entender a sociedade contemporânea.

Nesse sentido, alguns museus são especificamente projetados para possibilitar o processo educativo, tanto de crianças quanto de adultos, e dessa forma vão modernizandose para serem atrativos, acompanhando as transformações políticas, sociais, culturais e econômicas da sociedade. Ao mesmo tempo, o museu também passou por reflexões conceituais procurando se adequar aos processos educativos na sociedade, que são contínuos e refletem a necessidade de contato com o meio digital.

Enquanto alguns deles buscam apenas divulgação de seus acervos e exposições por meios eletrônicos, outros buscam na interatividade uma forma efetiva de atração de novos públicos e reconquista dos antigos, como é o caso do Museu de História Natural de Londres [1].

Segundo Shedroff [2], a interatividade provê capacidade de resposta e realimentação; controle das pessoas sobre suas experiências em diferentes graus; possibilidades de criatividade e produtividade e as práticas de comunicação e adaptabilidade.

Nesse sentido, o processo interativo deve, de fato, envolver a atenção do público, ou seja, se este não interagir (não agir continuamente desenrolando uma sequência de ações interconectadas), a mensagem hipermidiática não se exerce. $\mathrm{O}$ meio emudece, ao contrário de outros meios cuja leitura não exige encadeamento de "atos de decisão". [3]
Dessa forma, percebe-se nos chamados museus interativos uma aproximação da concepção pedagógica construtivista à medida que propiciam o envolvimento intelectual dos usuários, destacando o papel da ação do sujeito na aprendizagem e buscando a ampliação e evolução dos modelos mentais sobre os fenômenos [4]. Uma forma interessante de se promover a interatividade em museus é através de jogos educativos computadorizados, formas lúdicas de aprendizagem, que incentivam os usuários à construção de estratégias e aos processos de pesquisa, e geram novas habilidades ao jogador. A interatividade dos jogos faz com que sejam um ambiente agradável e motivador [5].

Nesse sentido, o presente trabalho apresenta a concepção, desenvolvimento e implementação de um jogo educativo em Realidade Aumentada para um Museu Interativo.

\section{REALIDADE AUMENTADA}

A Realidade Aumentada é uma particularização da Realidade Misturada, que consiste na sobreposição de objetos virtuais tridimensionais, ou não, gerados por computador em um ambiente físico, realizada em tempo real, por intermédio de dispositivos tecnológicos [6].

Pode ser definida ainda como:

- o enriquecimento do ambiente real com objetos virtuais, usando algum dispositivo tecnológico, funcionando em tempo real [7];

- uma melhoria do mundo real com textos, imagens e objetos virtuais, gerados por computador [8];

- a mistura de mundos reais e virtuais em algum ponto da realidade/virtualidade contínua, que conecta ambientes completamente reais a ambientes completamente virtuais [6];

- um sistema que suplementa o mundo real com objetos virtuais gerados por computador, parecendo coexistir no mesmo espaço e apresentando as seguintes propriedades:

○ combina objetos reais e virtuais no ambiente real;

- executa interativamente em tempo real;

- alinha objetos reais e virtuais entre si;

- aplica-se a todos os sentidos, incluindo audição, tato e força e cheiro [9].

Em suma, a RA pode ser definida como uma tecnologia por meio da qual se incrementa ou aumenta a visão que um 
utilizador tem do mundo real com a adição de imagens virtuais, usando técnicas de visão por computador e de Computação Gráfica/Realidade Virtual, resultando na sobreposição de objetos virtuais com o mundo real $[7 ; 9 ; 6]$.

Diferentemente da Realidade Virtual, que transporta o usuário para um ambiente virtual, a RA mantém o usuário no seu ambiente físico e transporta o ambiente virtual para o espaço do usuário, permitindo a interação com o mundo virtual, de maneira mais natural e com a vantagem de não ter necessidade de treinamento ou adaptação [10].

As pesquisas em RA tiveram seu inicio na década de 60, porém, apenas recentemente, devido aos avanços na tecnologia e possibilidade de equipamentos móveis, sistemas de RA começaram a aparecer no dia a dia das pessoas. Atualmente pode-se ver sistemas de RA aplicados em diversas áreas, tais como entretenimento, educação, propagandas, entre outras [13].

\section{A PROPOSTA INTERATIVA}

\section{A. Centro de Memória da Contabilidade Paulista}

O Centro de Memória da Contabilidade Paulista existe desde 2001, criado pela gestão 2000-2001 do Conselho Regional de Contabilidade de SP em conjunto com o IPH (Instituto de Recuperação do Patrimônio Histórico da Cidade de São Paulo) e a então Secretaria de Recuperação de Bens Culturais do Estado de São Paulo.

O Centro apresenta informações sobre a criação, a instalação do CRC SP e o trabalho desenvolvido pela entidade. Tudo isso, entrelaçado com acontecimentos históricos, políticos e culturais em todo o mundo.

Em dezembro de 2011, no aniversário de 65 anos do CRC SP, o Centro de Memória foi reinaugurado em um novo espaço cuja proposta era tornar a contabilidade mais atrativa aos visitantes (em sua maioria estudantes).

Nesse sentido foi proposta então a realização de um jogo interativo em Realidade Aumentada.

\section{B. Desafios}

Por se tratar de uma peça a ser desenvolvida para um Museu Interativo ligado à área de Contabilidade alguns aspectos tiveram que ser considerados durante $o$ desenvolvimento deste projeto:

- a questão estética: o ambiente deveria ser atrativo para os usuários e de fácil utilização.

- a segurança, durabilidade e preservação das peças (marcadores e tabuleiro): a princípio, qualquer pessoa deveria ser capaz de utilizar as peças do jogo de forma segura e que não comprometesse a integridade das peças.

- o projeto arquitetônico do ambiente, incluindo sua iluminação e a instalação dos equipamentos para a visualização do jogo: a iluminação local deveria ser o suficiente para a identificação dos marcadores, porém sem afetar as áreas adjacentes no museu e a câmera deveria ser instalada numa posição que permitisse a identificação dos marcadores, porém, de forma esteticamente adequada.
- a relação entre a tecnologia e a contabilidade e a temática do jogo interativo: o jogo deveria ser simples e fácil de ser manipulado por crianças com idade pré-escolar.

Em relação à questão estética era sabido o interesse do público em geral nas aplicações em Realidade Aumentada, o problema que se colocava, porém, era a necessidade de uma adequação do sistema de projeção no qual a aplicação seria visualizada para que, mesmo sem ninguém interagindo no momento, o resultado visto fosse interessante e chamativo.

Para solucionar este problema foram desenvolvidos e modelados objetos tridimensionais animados que abrangiam toda a área de projeção da aplicação (uma grande parede).

O segundo desafio foi ainda mais complexo de ser resolvido. Por se tratar de uma entidade de classe, todo o processo de aquisição de materiais deve ser licitatório. Tais processos são longos. Então como criar marcadores que não fossem extraviados ou danificados?

A solução foi o desenvolvimento de um tabuleiro e a construção de "cadernos" de marcadores fixos à ele, conforme apresentado na Figura 1. Diferentemente do que foi feito no Museu de História Natural de Londres, onde procurou-se "esconder" os marcadores do público [14], neste caso, os marcadores fazem parte do jogo e são manipulados pelo público.

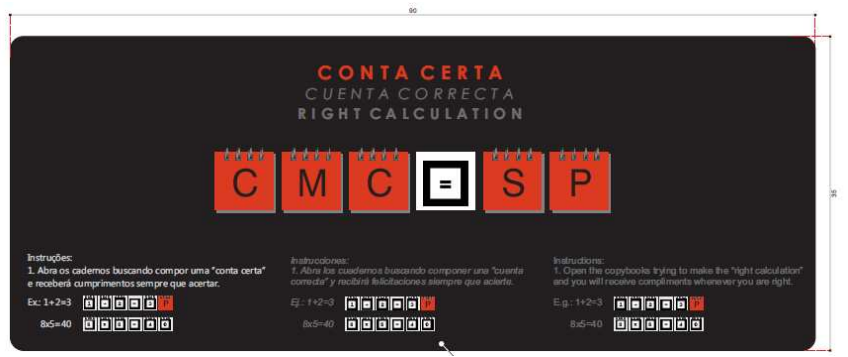

Figura 1: Tabuleiro Conta Certa

No desenvolvimento do tabuleiro outras duas questões se apresentaram: a necessidade de calibrar a câmera de captura dos marcadores de forma à identificar os marcadores principais sem identificar os ilustrativos contidos nas instruções do jogo, e desenvolvê-lo na cor preta, para que a projeção fosse esteticamente mais interessante e não afetasse a iluminação da sala.

A terceira questão a ser trabalhada era a de desenvolver um jogo que pudesse ser visualizado em uma sala de iluminação controlada e restrita, com equipamentos que ficassem fora do alcance das mãos e vistas dos visitantes.

Para resolver esse problema foi instalado um lustre metálico com design que remete aos lustres usados pelos contabilistas antigos. Este teve sua fiação trocada e nele foram instaladas a câmera (no lugar da lâmpada) e um jogo de lâmpadas de LED focal para que houvesse luminância suficiente para a captura e identificação dos marcadores pela câmera. Este foi afixado no forro da sala por um tubo metálico para que não houvesse balanço. O tabuleiro foi afixado em uma mesa antiga e escura de contabilista para garantir a boa captura e visualização. 
A última questão a ser resolvida era a de como fazer um jogo que fosse simples e, ao mesmo tempo, fizesse referências às temáticas da vida cotidiana do contabilista. Para tanto foi desenvolvido um jogo de aritmética simples cuja manipulação fosse simples e interessante principalmente para crianças em idade pré-escolar mas que pudesse também ser utilizado por crianças mais velhas e até adolescentes (a maioria do público), quanto para estudantes de contabilidade, contadores e público em geral. Consiste, então, na resolução de contas simples, mas numa aplicação de aspecto estático sedutor. Um esquema do ambiente é apresentado na Figura 2. Todo o hardware necessário está instalado na sala e o usuário não precisa utilizar qualquer tipo de equipamento durante o jogo. $\mathrm{O}$ funcionamento do sistema será discutido posteriormente nesse trabalho.

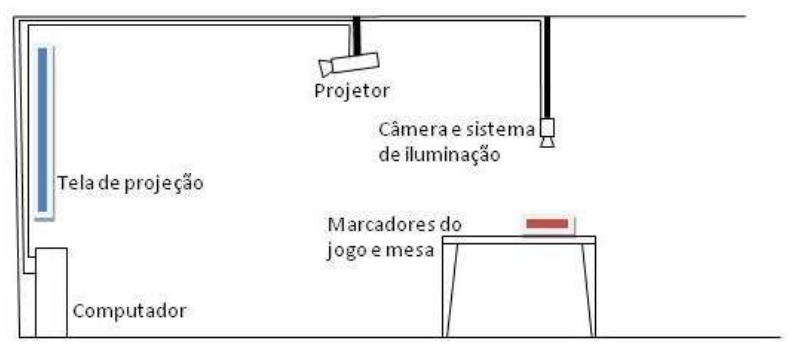

Figura 2: Esquema de instalação do jogo Conta Certa.

\section{DESENVOLVIMENTO do Sistema}

Um outro desafio no desenvolvimento do sistema Conta Certa está no fato de que não bastava apenas identificar os marcadores utilizados na mesa, mas ainda deveriam ser interpretados semanticamente para verificar se a conta proposta estava correta ou não, implicando, neste caso em um processo típico de visão computacional.

O sistema Conta Certa foi desenvolvido, então, para permitir a interatividade em um ambiente no Centro de Memória da Contabilidade Paulista, onde usuários do museu, principalmente crianças, podem interagir com o sistema de forma lúdica, testando seus conhecimentos de aritmética básica.

A interação com os objetos virtuais é bastante atraente, mas para que ela se torne possível é necessário a utilização de um software com capacidade de observar o ambiente real (no caso via webcam), analisando os dados capturados e extraindo informações sobre a localização, orientação e interações sobre tais objetos.

O sistema desenvolvido analisa uma conta aritmética indicada na forma infixa e mostra ao usuário, usando técnicas de realidade aumentada, se a conta indicada está ou não correta.

Diversos softwares tem capacidade de fazer tal análise. O sistema em questão foi desenvolvido baseado no ARToolKit $[11,12]$. Foi utilizado como base o exemplo simpleVRML.c, disponível na pasta de exemplos do ARToolKit para fazer a detecção e apresentação de animações de realidade virtual. O código foi modificado no procedimento mainloop de forma a identificar os dígitos, operadores e a conta indicada.

O sistema utiliza três variáveis globais, uma variável do tipo flag que é utilizada para indicar se a conta apresentada ao sistema esta ou não correta e dois vetores para armazenar os marcadores presentes na cena e o valor da coordenada $\mathrm{x}$ de cada marcador na janela.

No loop onde é verificado o marcador de maior confidência são também capturados todos os marcadores encontrados e suas coordenadas no eixo x são armazenadas nos vetores globais do sistema. Uma vez detectados os marcadores são ordenados utilizando a coordenada x como referência. Após a ordenação, a informação semântica dos marcadores é extraída e a conta indicada pelos marcadores é verificada. Se não houver conta (operador entre os marcadores na segunda posição e o sinal de igual na quarta posição) ou se a conta estiver incorreta, a flag global recebe o valor 0 , caso contrário, se a conta estiver correta a variável recebe o valor 1 .

No processo de mapeamento dos marcadores com a câmera e a apresentação das animações o sistema verifica a flag, se o valor da variável for igual a 0 o sistema simplesmente mostra as animações dos dígitos e símbolos presentes na imagem, conforme indicado na Figura 3.

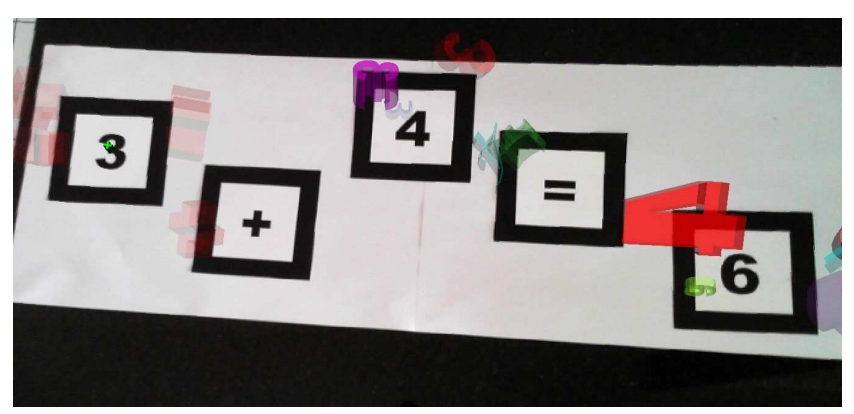

Figura 3: mostra uma cena típica do Conta Certa onde a conta está incorreta e as animações apresentadas são relacionadas aos dígitos e operadores apresentados.

Se a conta indicada na forma infixa estiver correta o sistema "apaga" as animações de dígitos e símbolos e apresenta a animação de sucesso, conforme apresentado na Figura 4.

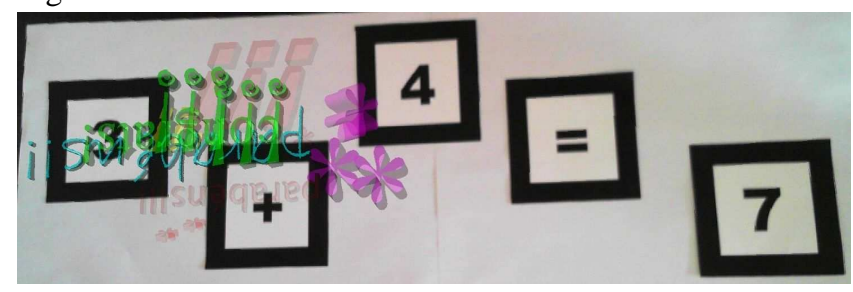

Figura 4:mostra uma conta correta avaliada pelo sistema Conta Certa.

Note que os marcadores não precisam estar alinhados na coordenada y da janela, basta que exista uma ordenação entre os marcadores na coordenada $\mathrm{x}$. 


\section{A INTERAÇÃO COM O PÚBLICO}

O Museu foi inaugurado em dezembro de 2011 e logo na inauguração já se pode perceber que os resultados esperados haviam sido alcançados. A sala na qual se encontra o jogo é a central do espaço e nela o visitante finaliza sua experiência no museu com um processo interativo com o sistema normalmente longo e prazeroso.

A fixação de câmera, tabuleiro e sistema de projeção permitem uma interação que praticamente não gera falhas no sistema de reconhecimento dos marcadores e, quando essas acontecem, o que o usuário precisa fazer é simplesmente fechar os cadernos de marcadores e reinicializar o processo para que a leitura volte a ser feita.

Os usuários entrevistados disseram achar interessante o jogo e bonita a projeção. Fazem contas certas e erradas propositalmente para ver a reação do sistema. Interagem sozinhos ou em conjunto.

\section{CONSIDERAÇÕES FINAIS:}

Os Museus interativos vêm se tornando cada vez mais presentes tanto nas grandes metrópoles, quanto em cidades de menor porta. A experiência das pessoas em geral, e das crianças em particular está fortemente ligada às relações que estabelecem com dispositivos interativos, como celulares, tablets e games de diversas naturezas.

A Realidade Aumentada, por sua vez, é uma tecnologia em expansão, com vasto campo de atuação, que engloba desde a publicidade até a educação.

Unir tal tecnologia ao desenvolvimento de um jogo interativo, que permite uma interação simples e de fácil aprendizado por parte dos visitantes do museu, ajuda a revitalização desses espaços que por algum tempo ficaram à margem das escolhas do público infantil no que diz respeito às suas escolhas de lazer e cultura.

Os jogos com Realidade Aumentada, nesse sentido, permitem que os usuários tenham uma visão enriquecida e ampliada do ambiente, podendo tornar atrativos assuntos complexos. Ao lidar com os objetos virtuais, o jogador estimula sua capacidade de percepção, raciocínio espacial e raciocínio formal, além de participar de uma experiência estética diferenciada.

Como trabalhos futuros pode-se aumentar a complexidade nas operações aritméticas propostas, assim como trabalhar no desenvolvimento de marcadores simplificados e reconhecimento de padrões de movimentos com a finalidade de tornar a experiência do usuário ainda mais rica.

\section{REFERENCIAS}

[1] Natural History Museum, Natural History Museum brings extint creatures to life before your eyes, press release, 10 Nov 2010.

[2] N. Shedroff. Experience Design 1, Indianapolis (IN): New Riders, 2001.

[3] A. Q. Baeta Neves. Novos Encatamentos: Hipermídia e Motivação. In: $7^{\circ}$ Congresso Brasileiro de Pesquisa e Desenvolvimento em Design. Anais do $7^{\circ}$ Congresso Brasileiro de Pesquisa e Desenvolvimento em Design. Curitiba, 2006.

[4] S. Cazelli; M. Marandino; D. Studart. Educação e Comunicação em Museus de Ciências: aspectos históricos, pesquisa e prática. In: GOUVÊA, G.; MARANDINO, M.; LEAL, M. C. (Org.). Educação e Museu: a construção social do caráter educativo dos museus de ciências. Editora Access/Faperj, Rio de Janeiro, p.83-106. 2003.

[5] A. L. Battaiola; F. E. Martins; M. P. Aguiar. Motivação e ludicidade: Uma possível abordagem para o design de jogos educacionais. In: Congresso Brasileiro de Pesquisa e Desenvolvimento em Design, número 8, São Paulo - SP - Brasil. Anais do 8 Congresso Brasileiro de Pesquisa e Desenvolvimento em Design. São Paulo. P. 1624-1633. 2008

[6] P. Milgram et. al. "Augmented Reality: A Class of Displays on the RealityVirtuality Continuum". Telemanipulator and Telepresence Technologies, SPIE, V.2351. 1994.

[7] C. Kirner ; R. Tori. "Introdução à Realidade Virtual, Realidade Misturada e Hiper-realidade”. In: Claudio Kirner; Romero Tori. (Ed.). Realidade Virtual: Conceitos, Tecnologia e Tendências. 1ed. São Paulo, v. 1, p. 3-20. 2004

[8] S. Insley. "Obstacles to general purpose augmented reality", ECE $399 \mathrm{H}$, Information Security \& Cryptography, Oregon, EUA, dezembro de 2003, disponível em http://islab.oregonstate.edu/koc/ece399/f03/final/insley2.pdf. . Acesso em: 15/05/2012.

[9] R. T. Azuma. "Tracking Requirements for Augmented Reality", Communications of the ACM, 36(7):50-51, July 1993.

[10] C. Kirner ; R. Tori . Fundamentos de Realidade Aumentada. In: Romero tori; Claudio Kirner; Robson Siscouto. (Org.). Fundamentos e Tecnologia de Realidade Virtual e Aumentada. 1 ed. Porto Alegre: Sociedade Brasileira de Computação - SBC, 2006, v. 1, p. 23-37.

[11] H. Kato, and M. Billinghurst, "Marker Tracking and HMD Calibration for a Video-based Augmented Reality Conferencing System", Proceedings of IWAR 99, pp. 85-94,1999.

[12] http://www.hitl.washington.edu/artoolkit/.

[13] Bimber, O., What's real about augmented reality? Computer, p. 2425, July 2012.

[14] Barry, A., Trout, J., Debenham, P. and Thomas, G., Augmented reality in a public space: the natural history museum, London, Computer, p. 42-47, July 2012. 